\title{
O espaço urbano como construção poética do sujeito Susanna Busato ${ }^{1}$
}

\section{O espaço perceptivo e a construção da cena}

Elaborar um roteiro de leitura do espaço urbano na poesia requer perceber de que modo a instância do sujeito faz representar-se na linguagem; e de que modo esta, em termos formais, marca a experiência cultural e estética do sujeito que lê a cidade, a partir de um lugar e de um tempo. A dimensão enunciativa do texto poético instaura a presença de um sujeito que vai se delineando como memória de uma experiência urbana e de uma experiência poética. Assim situado, esse sujeito inaugura no poema um espaço discursivo que opera procedimentalmente a imagem do corpo e da voz do(s) sujeito(s) como instâncias da construção do urbano. Este surge, pois, como o lugar da cena poética, ou seja, como "o meio pelo qual a posição das coisas se torna possível" (Merleau-Ponty, 1971). O espaço a ser explorado no contexto da poesia nesta proposta de estudo está ligado à percepção do sujeito, ao seu modo de sentir, e, por isso, ele não existe previamente, mas como uma instância movente que emerge no texto a partir do olhar do sujeito. Um espaço espacializante, no entendimento de Merleau-Ponty, ou seja, um espaço construído a partir das coordenadas dadas pela percepção do sujeito. Paul Zumthor (2014) fala em performance ao situar o sujeito como um corpo no espaço, que o inaugura e o sente na sua expressão primeira. Os objetos inaugurados a partir do olhar perceptivo do sujeito constroem um espaço reflexivo no qual as zonas de contato entre os objetos permitem ler a gestualidade dos corpos postos em relação. ${ }^{2} \mathrm{O}$ urbano inaugura-se, por sua vez, como um dado da paisagem e situa-se nessa tensão. Inaugura-se como signo e deve ser entendido num processo relacional, pois seu sentido só tem morada no poema, como elemento articulador de um espaço inaugural para um sujeito que o pensa.

\footnotetext{
${ }^{1}$ Doutora, professora de literatura brasileira da Universidade Estadual Paulista (UNESP), São José do Rio Preto, SP, Brasil. E-mail: susanna@ibilce.unesp.br

${ }^{2}$ Eu chamaria a atenção do leitor para a questão da "performance" a que Paul Zumthor se debruça e que nomeia como uma "operação cognitiva" (Zumthor, 2014, p. 44), pois situa o sujeito na cena e no seu imaginário. A poesia seria a expressão consciente dessa percepção do sujeito como um olhar original que se impõe diante do mundo e que, por fim, o constrói, o sujeito mesmo e o mundo.
} 
Ao elaborar um roteiro de leitura do espaço urbano na poesia brasileira contemporânea por meio do olhar do sujeito, faço-o em termos imagéticos e procedimentais. Uma pergunta se impõe antes de tudo: por que eleger o sujeito como o dispositivo desse roteiro de leitura? De modo objetivo diria que, ao lermos um poema, lemos a expressão da memória de uma sensação. A sensação, segundo MerleauPonty (2009), é como a célula viva da relação entre o eu e o mundo. E é pela dimensão lírica do poema que se constrói um sentir o mundo com o corpo. Um corpo-memória que se traduz em corpo-palavra.

A poesia do poeta paulistano Fábio Weintraub ${ }^{3}$ privilegia os vieses, as dobras do espaço urbano, que emergem das camadas do sentir que se objetiva nas coisas como imagens de um humano que se descobre não mais onipotente, mas impotente diante do mundo e de si próprio. Em outras palavras, o espaço urbano que se desenha na poesia de Weintraub só existe para um sujeito que o pensa num aqui e agora. A noção de "ponto de vista" se faz pertinente nesse contexto, pois, ao pensar a cena no momento do olhar, uma imagem particular do objeto percebido irá ser gerada. Posso, portanto, falar de qualidade material do discurso poético que plasma o corpo ou os corpos dos sujeitos em relação como palavra. A palavra deflagra, pois, as linhas de um espaço de realidade imagética que se desdobra por meio de um tom expressionista, eu diria, ou seja, por meio de um sentir o humano no outro, sua tragédia, sua violência, seus paroxismos. ${ }^{4}$ É, pois, a presença de um "fazer pensar", de "provocar atos internos", movimento intrínseco à poesia, como afirmaria também Paul Valéry, em A serpente e o pensar (1984), que a poesia de Weintraub percorre, na aparente simplicidade de sua sintaxe poética. São as anotações miméticas do cotidiano dos sujeitos em situação limite, em que seus corpos se oferecem ao olhar nas cicatrizes

\footnotetext{
${ }^{3}$ Fábio Weintraub, nascido em 24/8/1967 em São Paulo, SP, é poeta, editor e ensaísta. Tem formação em psicologia pela USP. Tem poemas publicados em antologias diversas no Brasil e exterior. É autor de Toda mudez será conquistada (SP: Massao Ohno, 1992) e do livro Sistema de Erros (Arte PauBrasil, 1996). Seu livro Novo Endereço (Nankin Editorial, 2002) recebeu dois prêmios literários e uma tradução bilíngue para o espanhol; e Baque $(34,2007)$ foi produzido a partir do prêmio Bolsa de Incentivo à Criação Literária do Governo do Estado de São Paulo, na categoria poesia.

${ }^{4}$ Para pensar as relações entre o sujeito e o espaço urbano como elementos de identidade e/ou alteridade: "Sansot jamais se esquece de que se o homem é à imagem de sua cidade, a cidade é, por sua vez, a imagem do homem: edificada por ele, marcada em todos os seus lugares pelo seu trabalho, suas penas e suas alegrias, por tudo que a presença humana deposita sobre suas pedras" (Dufrenne apud Sansot, 2004, p. 13, tradução nossa).
} 
visíveis das descrições, que o sujeito lírico registra no seu exercício de olhar o outro, e também nas cicatrizes invisíveis, suspensas como sensação e reflexão nas cenas cortadas pelo diálogo apanhado de passagem. O registro quase direto da memória sensitiva do sujeito passante em Novo endereço (2002) e em Baque (2007), livros dos quais escolho os poemas que serão alvo de minha leitura, supõe uma sintaxe de igual postura, direta, objetiva, curta, imagem formal que plasma como documento, como crônica, a cena urbana e seus personagens.

Os três poemas que apresento - "Calçada", "Demolidora 3 Irmãos" (de Novo endereço) e "Fotografia" (de Baque) - trabalham, na sua construção espacial, com a noção da espacialização do "instante", fornecendo ao olhar as referências que se desdobram e constroem uma imagem do urbano particularizada no seu drama, no seu horror, numa perspectiva nada salvadora do mundo. A dicção do sujeito lírico nos poemas desaloja o discurso sobre si mesmo para, em terceira pessoa, dirigir-se ao outro. A subjetividade lírica nesses poemas (e que, de certa forma, estão presentes nos demais poemas dos livros citados) mira-se em tomada especular para com o outro, ou seja, como expressão individual, ainda resiste ao lugar-comum da expressão poética coletiva ao flagrar no outro algo que Adorno mencionaria como aquilo que ainda não foi desfigurado pela "inautenticidade social" (Achcar, 1994, p. 38). Os poemas que analiso aqui são poemas que inserem o sujeito como um olhar inaugurador de uma cena urbana que traspõe o mero reconhecimento que temos do urbano, para projetar nossos sentidos no interior de um espaço sensível, um espaço de tensão que se oferece como um instante pregnante, como aquele que Manuel Bandeira representou no gesto largo e demorado do sujeito particularizado que se descobriu diante do morto que passava em frente ao café, onde as demais pessoas se distraíam, voltadas para si mesmas. É um momento único no que concerne ao estado perceptivo do sujeito que se dá conta do mundo ao redor, situando-se como agente da descoberta.

O que ocorre nos poemas aqui, portanto, é que o objeto do olhar ocupa lugar privilegiado, pois o sujeito apenas consegue se expressar a partir da configuração de sua percepção do mundo. É no seu modo de perceber o outro que a expressividade de sua poesia se apresenta. A objetivação do olhar imprime no outro o assombro de si mesmo, do sujeito que percebe e sente a cena. Afastado da cena, desenha a tragédia 
como um flagrante temporal que se espacializa nas figuras da expressão. A poesia nasce desse impacto, da cena e do olhar.

Em suma, o sujeito lírico, na poesia de Weintraub, deixa evidente seu olhar para com seu corpo colocado em estado de escuta do outro e de si mesmo. Em vez de interrogar-se, é ao outro que se lança; ao interrogar o outro com seu olhar, é a si mesmo que elege como "solidário" e "imprestável", como um sujeito "de passagem", que se mira no olho do "camundongo cego" que jaz à espreita junto ao muro, no fim da rua: imagem no poema "Calçada" da não saída, da tragédia pontuada num dos vértices do espaço encenado do urbano.

\section{Cena 1: o espaço de fora}

\section{Calçada}

depois que ele entrou no prédio

e fechou a porta

a calçada partiu novamente a toda velocidade

conduziu o vento até a estação mais próxima contornou cinco mendigos e os respectivos cachorros lavou o chão do último bar

só foi morrer muito adiante no muro da praça deserta onde a fome devasta a fronte de um camundongo cego (Weintraub, 2002, p. 20)

Evidencio, primeiramente, no poema, três instâncias espaçotemporais, construídas em oposições: o dentro e o fora; o antes e o depois; o chegar e o partir. Tais oposições estabelecem a dinâmica da construção da perspectiva. Dois personagens se separam ao mesmo tempo: o sujeito, que entra no prédio e fecha a porta; e a calçada, que segue seu trajeto "a toda velocidade". O movimento se objetiva em relações de contraste: a repulsão marca o ponto de fratura entre os sujeitos: o "ele" e a "calçada" no momento entre o antes e o depois. A 
ação imposta no "depois" é que marca a construção do espaço urbano como lugar da cena dramática. Não é um "caminhar" que os versos desenham, mas uma fuga "a toda velocidade". Careri (2014, p. 10) lembra-nos de que a ação de atravessar o espaço "nasce da necessidade natural de mover-se para encontrar alimento e as informações necessárias para a própria sobrevivência". Mas esse movimento que é narrado/descrito pelo sujeito lírico se transforma numa forma de "errância", que eu diria ritual, pois "a calçada partiu novamente", de onde o aspecto da continuidade previsto no advérbio empresta à cena um dado de repetição, de continuidade.

O caminhar é uma arte que traz em seu seio o menir, a escultura, a arquitetura e a paisagem. [...] Hoje se pode construir uma história do caminhar como forma de intervenção urbana que traz consigo os significados simbólicos do ato criativo primário: a errância como arquitetura da paisagem, entendendo-se com o termo paisagem a ação de transformação simbólica, para além de física, do espaço antrópico (Careri, 2014, p. 10).

Sem desejar entrar no conceito de paisagem especificamente, creio ser oportuno afirmar que esta se delineia no poema por meio da ação de "partir", protagonizada pela calçada e coliderada pelo "vento" que vem dar à cena a dinâmica da ação do movimento deliberado e frenético dos verbos de ação que lhe antropomorfizam o gesto - "conduziu", "contornou", "lavou", "foi morrer" e "devasta". O espaço da paisagem pontuada pelas imagens vai se configurando como um dado que ultrapassa o mero referente antrópico para se definir como um lance aglutinador de referências que se associam num paradigma do baixo e do animalesco, elementos que irão matizar a cena de uma expressão caótica.

É, pois, sobre a esfera do espaço externo, daquilo que fica do lado de fora (o fora de campo sob a ótica do personagem que "entrou no prédio") que os versos avançam pelo olhar-câmera da calçada, a descrever/narrar, no passado, o caminho que se distancia do sujeito que entrou no prédio e se isolou do exterior. $O$ esquema seguinte pode ajudar a visualizar a dinâmica das oposições que nos levariam para o alcance de uma discussão sociocultural que pode contribuir para a leitura do poema, na sua diagramatização expressiva das relações homem-espaço urbano. Ainda que essa análise não prime por tecer essas considerações, faço valer o esquema, que poderá ser melhorado e discutido num desdobramento analítico: 


$$
\begin{aligned}
& \text { "ele" } \rightarrow \text { espaço fechado } \rightarrow \text { interior } \rightarrow \text { imobilidade } \\
& \text { "calçada" } \rightarrow \text { espaço aberto } \rightarrow \text { exterior } \rightarrow \text { movimento }
\end{aligned}
$$

Ao duplo movimento em fuga eu denominaria "cinematográfico" uma vez que os recortes de movimento que se seguem nos versos da segunda e da terceira estrofes atuam como enquadramentos de cena justapostos numa sequência por vezes acelerada, por força dos versos curtos (métrica entre 5 e 8 sílabas poéticas) e das imagens que emergem de um percurso ao rés do chão, num plano em close. Dessa forma, assistimos à cena em que "ele", personagem inominável, impessoal, "entrou no prédio/e fechou a porta" ( $1^{\circ}$ movimento); enquanto a personagem nomeada, pessoal, "calçada" "partiu novamente/a toda velocidade" ( $2^{\circ}$ movimento). O advérbio "novamente" resgata o sema da constância, da repetição, de caráter ritualístico, eu diria, pois como espaço público a calçada se situa no seio da esfera urbana como um lugar simbólico do encontro e da diferença; do intercâmbio e do resíduo; da passagem e da performance. ${ }^{5}$ Enceta a segunda estrofe o trajeto do espaço urbano/poético/imagético dessa calçada anímica, cuja presença é intermediada pelo olhar do sujeito lírico do poema, cuja voz, em $3^{\text {a }}$ pessoa, ao longo das estrofes, descreve o percurso por meio de elementos simbólicos que se situam na esfera marginal: mendigos, cachorros, água da lavagem do bar, muro e rato cego. O olhar do sujeito, como uma câmera que se aloja no olho da calçada, presentifica como linguagem o movimento, portanto, e, num tom narrativo do que já é passado, dá vida à calçada cuja estaticidade natureza de concreto e asfalto consegue mobilizar e dinamizar, na gama cromática dos verbos que iluminam, o que se esconde no espaço que se desaloja e se desdobra para um roteiro inesperado. $\mathrm{O}$ espaço percebido torna-se imagem de um corpo-sujeito que segue como linguagem o corpo-mundo metonimizado pela "calçada", num misto de memória e presentificação, como a perscrutar, no âmbito do movimento frenético e sem roteiro do percurso, um dado de violência que surpreende.

\footnotetext{
${ }^{5}$ Essas oposições emergem aqui sem antes haver de minha parte a consciência de que um estudo socioantropológico, bem como cultural e da arquitetura urbana, tenha de ser feito para que uma análise paralela ao poema possa ser elaborada e contribuir para pensar o sujeito no espaço urbano e suas idiossincrasias, tema que a poesia de Fábio Weintraub motiva a buscar, ainda que dessa investigação não resulte uma análise crítica do poético em si. Alguns estudos interessantes para adensar essa temática poderiam ser A casa e a rua, de Roberto DaMatta, bem como The death and life of great American cities, de Jane Jacobs, além do estudo de Francesco Careri Walkscapes: o caminhar como prática estética, como também o já mencionado livro de Pierre Sansot, Poétique de la ville.
} 
Podemos inferir que o sujeito, isolado no espaço interno do prédio não vê, ou não quer ver, o que há lá fora. Já no âmbito da calçada antropomorfizada, como se pode observar pelos verbos que constroem os predicados referentes a esse substantivo em posição de sujeito das orações ("a calçada partiu", "conduziu", "contornou", "lavou o chão", "só foi morrer"), há um movimento acelerado do trajeto que esse personagem de concreto persegue como se fosse insano e involuntário, independente da vontade. Pegando carona no vento, personagem do movimento e da aceleração (recolhe o sentido da locução adverbial do verso anterior, "a toda velocidade"), a sensação de fuga ${ }^{6}$ no poema se intensifica e nos faz visualizar/percorrer o roteiro novamente, traçado desse ritual cotidiano da rua, condensado pelo poema na sequência metonímica dos flagrantes. $\mathrm{O}$ vento como imagem daquilo que passa, que prossegue, intensifica o sentido do movimento no poema, que vai focalizar no caminho os elementos que se situam num espaço ao rés do chão: mendigos, cachorros, chão do bar, praça deserta, fronte devastada de um camundongo cego. Os elementos elencados no roteiro da calçada são elementos urbanos que projetam o espaço para um sentido de degradação. O ponto final dessa fuga deflagra a ausência de qualquer salvação. A calçada, ou seja, a vida lá fora, o espaço atirado ao seu destino cego, no seu percurso insano de fuga, apenas se depara no final de seu trajeto com um espaço vazio, como sugerem as palavras finais da última estrofe do poema.

\title{
Cena 2: as molduras do espaço
}

\section{Fotografia}

\author{
De cócoras \\ como quem ora \\ ou pragueja \\ sob a marquise \\ a mulher
}

\footnotetext{
${ }^{6}$ A fuga tem origem no momento em que o sujeito se fecha porta adentro do prédio, moldura urbana que o isola do espaço externo, que deixa de existir para ele, pois a ação toda que se edifica é a que é recolhida pela ação espaço-temporal de um contínuo que apenas existe no poema para o sujeito-lírico que lhe dá anima por meio de sua memória sensitiva e de sua experiência. O poema nasceria do que inexiste para o sujeito urbano que se isola da calçada, metonímia da cidade, da vida mundana e do caos, como bem deixam evidentes as imagens.
} 
Oculta
pelos caixotes
embriagada
entre sobras de repolho
Pela calçada em declive
cachorros lambem o chorume

Penso na foto

franzindo a testa

solidário

imprestável (Weintraub, 2007, p. 34)

O título desse poema oferece-nos uma moldura: a fotografia, registro de um flagrante, de um olhar que flana, que busca na imagem a grafia de um corpo. Num segundo momento, a fotografia é a moldura que marca a distância entre o sujeito observador e o objeto observado. O movimento do olhar do sujeito lírico inicia sua trajetória de flanar no espaço urbano e, em terceira pessoa, registra o que vê. Constrói aos poucos, de acordo com o trajeto que a percepção vai transpondo para a reflexão final do poema, uma descoberta crítica da própria nulidade do sujeito do olhar frente ao assombro, que limita nele uma ação efetiva frente à cena. A objetividade do olhar do sujeito lírico acaba, num movimento sensível, por resgatar um dado mítico na figura da mulher sob a marquise aninhada entre os caixotes.

O tempo presente da enunciação colabora para a descoberta de cada detalhe da imagem, que se dá a ver no momento mesmo de sua leitura, e não como memória narrada. $\mathrm{O}$ arranjo sintagmático dos versos contribui para que, metonimicamente, entremos em contato com os elementos da cena que vão compor a imagem. A personagem foco é "a mulher". Passamos a compor o espaço, por meio do roteiro de caracterizações dessa mulher em termos físicos e em termos de localização pontual. Na primeira estrofe temos os atributos que a caracterizam e que a localizam no espaço: "de cócoras", "como quem ora", "ou pragueja" e "sob a marquise"; "oculta/pelos caixotes" e "embriagada/entre sobras de repolho". Logo percebemos que o espaço emoldurado pela cena insere a personagem num ambiente em que a ideia de "resíduo" presente em "entre sobras de repolhos" é associada espacial e semanticamente à mulher. Eis o primeiro dado de sentido da imagem a que temos acesso. 
O lugar ocupado pela mulher nesse ambiente é, pois, emoldurado pelos elementos da cena: "sob a marquise", "oculta pelos caixotes" e "entre sobras de repolhos". O espaço recluso no qual se insere é também delimitado pela posição do seu corpo - "de cócoras" - e pelo seu estado físico, de isolamento interno - "embriagada". Esse campo delimitador de seu corpo no espaço da cena - "embriagada" - é reforçado pela ação incerta observada pelo sujeito que vê a cena: "como quem ora/ou pragueja". Flagra o observador da cena um caráter antitético na sua postura, cuja irresolução fica manifesta. A incerteza gerada carrega de tensão a figura da mulher e adquire uma dimensão objetiva. $\mathrm{O}$ olhar do observador apenas elege dois valores para nomear o que percebe - orar ou praguejar, o sagrado versus o profano -, com os quais interpreta a figura da mulher, sem se decidir por nenhum deles. A imagem dessa mulher acocorada e embriagada leva minha leitura a perceber o traço espacial de natureza corporal como uma moldura que a separa do ambiente externo da rua, o espaço urbano, o espaço coletivo, cuja menção só é indiciada por meio dos elementos da cena. Outra oposição aqui se insere, portanto: o privado versus o coletivo. E é nesse ambiente privado do sujeito da cena que o olhar do sujeito observador flagra traços que redimensionam e amplificam, na expressão, o que se poderia considerar apenas como um dado da paisagem, tomado no contexto do coletivo. Ou seja, a cena que o observador tem diante de si poderia passar despercebida no universo do coletivo, pois há tantos indivíduos como essa mulher a ocupar espaços e a traçar as molduras no universo urbano. A "ruína" como o segundo sentido da imagem nesse contexto aproxima-se da esfera do sentir do sujeito, que na sua percepção pensa o outro como a querer compreender sua estranheza, que está justamente naquilo que desaloja e que indetermina, que cinge a linha do tempo presente do sujeito como um corte. É o tempo retilíneo que se rompe pelo assombro de que se vê tomado o sujeito, cuja objetividade de expressão dá luz à cena.

A questão que se coloca aqui é como pode essa figura emergir do lugar onde está reclusa - "de cócoras", "sob a marquise", "oculta" e "embriagada"? Onde está o sujeito que lhe dá presença no poema? Perguntar o lugar do sujeito que dá luz com seu olhar à cena é o mesmo que perseguir a luz com que o pintor percorre o quadro e dá ênfase à cena que invade nosso olhar. $\mathrm{O}$ espaço privilegiado do sujeito que tem acesso à cena rompe exatamente com as molduras espaciais, ou seja, as sociais e emocionais, molduras que impedem o olhar de sentir o outro. 
As palavras e o modo de estruturá-las no poema revelam o olhar que dá luz à cena. É pela observação fina e objetiva que a cena se ilumina. A estrutura do poema de Weintraub aqui é simples. Não há, por parte do sujeito lírico, um desejo de desviar-se do objeto focado, ou seja, não lança mão de metáforas ou digressões para extrair da figura o foco em sua internalidade. Na verdade, basta ao observador documentar o que vê e, nesse procedimento conciso de descrição, construir analogamente uma estrutura que se aproxima do caráter do flagrante da imagem e do seu modo de espantar-se com o disforme e marginal.

As cinco estrofes do poema organizam os versos curtos cuja métrica varia entre o dissílabo e o heptassílabo. Prevalece um ritmo desacelerado por conta dos acentos que incidem em sílabas sonoramente formadas por consoantes que reverberam entre si e que constroem a assonância de vogais abertas e fechadas. Por exemplo, percebemos esse recurso em:

de cócoras /ó/ e /ô/
como quem ora /ô/ e /ó/
ou pragueja /ô/7

As rimas toantes ${ }^{8}$ em "cócoras" / "ora" (versos 1 e 2 da estrofe 1) realizam também um encontro morfovisual do conjunto, ou seja, "ora" está em "cócoras", o que pode sugerir o encontro entre a postura do corpo - estar de cócoras, e a ação - orando. A aliteração das guturais /k/ também colabora para a atmosfera de primitivismo da figura flagrada em um comportamento desviante de uma condição humana mais exultante. A sintaxe, no entanto, continua no verso seguinte, promovendo a possibilidade de a ação ser protagonizada por outro verbo - "pragueja" em que a sílaba tônica tem sua consoante sonora reverberada por seu par homorgânico surdo em "quem" do verso anterior. Esse jogo sonoro de oposições enfatiza o dado de incerteza flagrado pelo sujeito: a mulher observada se apresenta ambígua na sua atitude acocorada, "como quem ora/ou pragueja". Tem-se aqui um traço expressionista da figurativização da cena ao enfatizar esse aspecto primitivo da personagem e ambíguo, distorcido, o que gera tensão na imagem.

\footnotetext{
${ }^{7}$ As sílabas sublinhadas referem-se aos acentos fortes (ou sílabas longas) dos versos.

${ }^{8}$ A rima toante aqui é flagrada no som da tônica em /ó/ e, ludicamente, as duas palavras ("cócoras" e "ora") nos mobilizam o olhar para o aspecto visual que se repete em "-ora", ainda que não construam uma rima entre si.
} 
O recurso sonoro pontua no poema os versos que compõem o espaço das figuras na concisão com que se oferecem ao leitor. A natureza plástica do conjunto vai criando o modo como o sujeito sente a cena, pois a sintaxe prima por apresentar os objetos do olhar de modo a adquirirem uma individualidade, como elementos simbólicos do "resíduo" e da "ruína". Flagra o sujeito observador uma cena urbana, a partir da qual, em seus aspectos constituintes, vai tecendo analogias e desencadeando o horror. Assim: o elemento humano (a mulher) é situado na mesma calçada/cena em que "cachorros lambem o chorume"; a calçada em declive reforça o desequilíbrio/desvio/marginalidade da figura acocorada que ora ou pragueja; as "sobras de repolhos", juntamente com os caixotes, emolduram e sugerem o nivelamento da mulher ao que fede e apodrece. Os caixotes que a ocultam sob a marquise situam-na num espaço reduzido e amortalhado. Junto a resíduos a personagem se situa para configurar a ruína no conjunto da composição. $O$ olhar pontual do sujeito que vê a cena flagra algo mais na sua descrição do que meramente uma mulher anônima na paisagem do cotidiano das ruas. Flagra nesse personagem a ruína de si próprio ao perceber nela o fragmento que a caracteriza e que está no olhar que a identifica em moto ambíguo. Em outras palavras: o objeto chama o sujeito a ver.

A mulher, na esfera do parecer orar ou praguejar, adquire uma dimensão aurática que a situa num espaço atemporal, que no poema é alçado/nomeado de "fotografia". Esse espaço permite o distanciamento e a ambiguidade que se alarga, ao pontuarmos o fato de que, na mulher, estão o poder gerador da vida e também, pelo lado mítico, o poder conflagrador da morte, parecendo bruxa. A oposição sagrado-profano, advinda dos versos "como quem ora/ou pragueja", remete, portanto, a outra oposição: mulher-bruxa. Assim:

$$
\begin{aligned}
& \text { Orar } \rightarrow \text { sagrado } \rightarrow \text { vida } \rightarrow \text { mulher } \\
& \text { Praguejar } \rightarrow \text { profano } \rightarrow \text { morte } \rightarrow \text { bruxa }
\end{aligned}
$$

A distância criada pela objetivação da cena gera no sujeito uma atitude do não saber fazer, implicada no desejo de querer fazer, a partir do momento em que se autodeclara "solidário" frente à cena. Esta toma uma configuração isenta de excessos. O olhar que adentra o espaço do sujeito observado - a mulher - é de apreensão curiosa e atenta, por isso a isenção do excesso. Não parece espantar-se, ou melhor, parece não querer espantar-se, à medida que vai descobrindo o que está oculto entre os caixotes. Provavelmente o assombro não deseja adquirir o tom 
do alarde, porque o espanto causado é, seguramente, interno. É o que nos falam os versos finais do poema:

Penso na foto

franzindo a testa

solidário

$$
\text { imprestável }
$$

Aqui, o sujeito surge como que engajado na totalidade da cena por sua atitude de preocupação - um sujeito do "querer fazer" -, o que nos levaria a pensar num sujeito do "dever fazer": "franzindo a testa / solidário". Define-se, no entanto, como sujeito de um "não poder fazer". Assim também acontece com a mulher da cena, sujeito "imprestável", porque não age e se oculta e se isola em si mesmo, numa atitude do "não poder fazer" ou do "não querer fazer". Da parte do sujeito observador, posso dizer que se define de igual maneira: sabe que deve fazer, mas não pode fazer. Ambos parecem igualar-se nessa esfera urbana por seu caráter "imprestável". Ambos marginais de si mesmos.

\section{Cena 3: o espaço interior}

\section{Demolidora 3 Irmãos}

vendem-se portas:

portas sem costas

portas na brisa

aleijadas

viúvas do esqueleto das salas

(e as maçanetas

são torneiras gotejantes

molhando mãos transtornadas)

portas de exportação

portas de exílio ou transplante

ruínas móveis

à espera de novos reinos

(quem se importa 


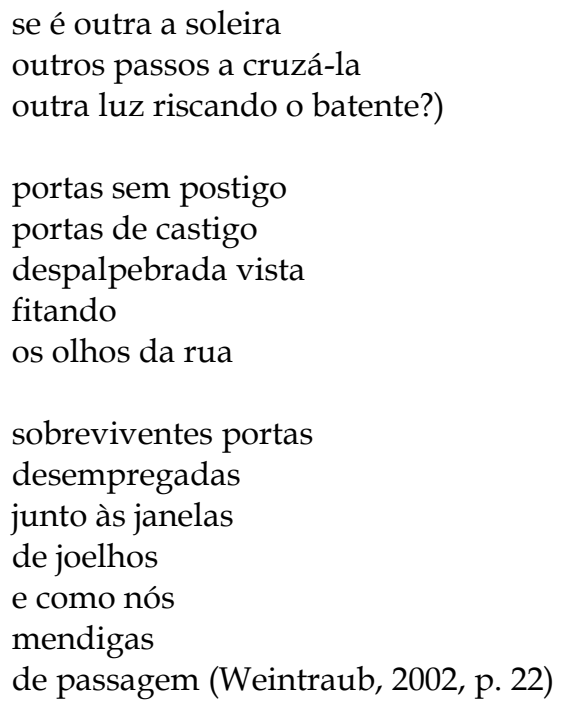

A desreferencialização dos objetos é um procedimento poético que nasce da falta, daquilo que não se dá a ver. Merleau-Ponty nos recorda de que o pintor Cézanne afirmou certa vez que "a natureza está no interior" (Merleau-Ponty, 2009, p. 23), ou seja, o invisível apenas se dá a ver para o sujeito que se lança a uma busca: desentranhar das referências do mundo o que se situa no âmbito das relações entre o corpo e o olhar. Nessa busca, afirma Merleau-Ponty, "qualidade, luz, cor, profundidade, que estão ali perante nós, só lá estão porque despertam um eco no nosso corpo, porque ele as acolhe" (MerleauPonty, 2009, p. 23). O olhar do sujeito, seu corpo e seu sentido, se expressa por meio de um penetrar o outro para desentranhar dele algo que pertence à esfera do próprio sujeito, sua humanidade perdida. Mas, para isso, procede a um movimento de desreferencializar os objetos, torná-los estranhos em seu sentido, para que o encontro com o que se acredita ausente seja possível.

No poema "Demolidora 3 Irmãos", o verso "vendem-se portas" abre a moldura do poema para um processo imagético, que amplia o sentido para um universo metafórico que desaloja a expressão prosaica de seu sentido único. $\mathrm{O}$ poema vai desconstruindo a expressão-chave "vendem-se portas" por meio de um procedimento que visa explorar no objeto "porta" o dado de fratura. A porta deslocada de seu contexto assume no poema o papel de signo construtor de um discurso sobre a 
perda, sobre a condição humana da fratura, enquanto corpo, senão de porta, de homem, que sente e sofre a perda. Novamente a temática da crise nasce da poesia de Weintraub como um traço que constrói a espacialização do assombro no olhar do sujeito nas imagens que emergem de sua reflexão íntima sobre os objetos. Não é mais a descrição objetiva e nítida que se impõe, mas o espaço interno desses objetos, a saber, de humanidade projetada.

Assim, a "porta" passa a ter caracteres humanos na sua decomposição pelo discurso: "sem costas", "aleijadas", "viúvas", "de castigo", "despalpebrada vista", "fitando/os olhos da rua", "sobreviventes", desempregadas", "de joelhos", "mendigas". As analogias vão criando os traços icônicos do objeto: a tragédia é humana e a tensão se revela no inanimado. Destituída de sua função, desreferencializada, o elemento "porta" vai se encontrando com o elemento "humano", também destituído de seu contexto e circunscrito na imagem do abandono, da fratura, da queda, sem mais função: o símile assinala sua sobrevivência na inércia, "junto às janelas/de joelhos/e como nós/mendigas/de passagem". A cena final - "mendigas de passagem" - é a imagem que o sujeito recolhe da condição de um estado de existência no qual inclui também o leitor "como nós" - e projeta nas "sobreviventes portas" a tragédia.

\section{O espaço como memória}

A poesia nasce da memória de uma sensação. Esse dado perceptivo invade o sujeito e o situa no mundo. A expressão poética desse mundo implica a memória sensível que é resgatada por esse novo ato de "perceber as coisas", como se elas novamente se presentificassem ao sujeito. É de um tempo presente, pois, de que trata a poesia. E também de um espaço que se inaugura como o lugar da cena percebida pelo sujeito no trajeto que sua memória resgata no corpo sensível. Assim é que os poemas que analisei perfazem esse roteiro espacial. A camada sintática é responsável por construir a expressão objetiva do discurso no âmbito reduzido do verso, tensionando a cena. No caminho descritivo da imagem que vai pouco a pouco iluminando esse espaço, podemos perceber pela semântica a subjetividade do olhar que revela a perplexidade dos elementos na relação espacial que os reúne por meio de seus elementos figurativos. Eis a plasticidade discursiva concorrendo para o traço expressionista flagrado no discurso. O presente no flagrante 
do horror, no espanto e na imobilização causada pelo impacto das cenas, pode apresentar-se de várias formas. Mas algo o equaciona nos poemas lidos. E esse algo é o "resíduo" que restauramos: o espanto e o horror figurativizados pelo grotesco da imagem, pelo assombro do sujeito, pelo traço, nesses poemas, de concisão e tensionamento da expressão do impacto. O traço lírico nos poemas de Weintraub parece circunscrever, na temática que desenvolve, um percurso sem saída. Discurso da constatação da falta, da ausência, da miséria do outro que é também nossa. Assim se configuram os poemas analisados aqui, "Calçada", "Fotografia" e "Demolidora 3 Irmãos".

Se declarei que perceber é a célula viva da relação entre o eu e o mundo e, também, que nesse ato está implicado um corpo-memória que se traduz em corpo-palavra, traço que vai se construindo na esfera de um parecer carregado do sujeito-corpo que é influenciado pelas imagens exteriores do mundo da experiência de um sentir, fiz por percorrer na leitura das imagens dos poemas de Fábio Weintraub, pelo menos para mim e para o olhar que lanço para a poesia contemporânea brasileira, um dado que sugere a presença de um sujeito que segue preso à memória de seu tempo contemporâneo, sobretudo ao que o religa, em termos de experiência, ao cotidiano da cidade, a elementos de uma problemática social e humana, que não mais tece a utopia, pois, no flagrante das cenas, vislumbra a não saída do impasse a que se vê atado: a fragilidade da vida, a morte iminente, a sobrevivência ao caos, a ruína como moto perpétuo de um tempo e a reflexão contínua de um aqui e agora que apenas tece o assombro da existência humana.

\section{Referências}

ACHCAR, Francisco (1994). Lírica e lugar-comum: alguns temas de Horácio e sua presença em português. São Paulo: Ed. USP.

CARERI, Francesco (2014). Walkscapes: o caminhar como prática estética. Tradução de Frederico Bonaldo. São Paulo: Gilli, 2014.

DaMATTA, Roberto (1979). A casa e a rua. In: DaMATTA, Roberto. Carnavais, malandros e heróis. Rio de Janeiro: Zahar.

JACOBS, Jane. The death and life of great American cities (1961). New York: Random House. 
MERLEAU-PONTY, Maurice (1971). Fenomenologia da percepção. Tradução de Reginaldo di Piero. São Paulo: Freitas Bastos.

MERLEAU-PONTY, Maurice (2009). O olho e o espírito. 7. ed. Lisboa: Vega.

SANSOT, Pierre (2004). Poétique de la ville. Paris: Petite Bibliothèque Payot.

VALÉRY, Paul (1984). A serpente e o pensar. Tradução de Augusto de Campos. São Paulo: Brasiliense.

ZUMTHOR, Paul (2014). Performance, recepção, leitura. Tradução de Jerusa Pires Ferreira e Suely Fenerich. São Paulo: Cosac Naify.

WEINTRAUB, Fábio (2002). Novo endereço. São Paulo: Nankin, 2002.

WEINTRAUB, Fábio (2007). Baque. São Paulo: 34, 2007.

Recebido em julho de 2014.

Aprovado em outubro de 2014.

\section{resumo/abstract}

\section{O espaço urbano como construção poética do sujeito}

Susanna Busato

Este é um estudo crítico-analítico acerca de alguns poemas do poeta brasileiro Fábio Weintraub em termos da construção do espaço da poesia como um olhar crítico e poético do sujeito. $\mathrm{O}$ aspecto lírico do trabalho do poeta é objetivo e sensível ao dirigir-se às cenas urbanas nas quais os objetos desempenham um papel como imagens de um cotidiano das cidades cujo espaço é performatizado como drama do próprio sujeito que olha a cena.

Palavras-chave: espaço, cidade, poesia contemporânea, Fábio Weintraub.

\section{Urban space as a poetic construction of the subject}

\section{Susanna Busato}

This is a critical and analytical study about some poems written by the Brazilian poet Fábio Weintraub concerning the construction of the poetic space as a critical and poetical view of the subject. The lyric aspect in the poet's work is objective and sensitive towards urban scenes in which all the objects play a role 
as images of the cities' routine, in which space is performed as the drama of the subject who sees the scene.

Keywords: space, city, contemporary poetry, Fábio Weintraub. 